\title{
The Influence of Solute Atoms on the Stacking Fault Energy in $\alpha \mathrm{Cu}-\mathrm{Al}$ Alloys*
}

\author{
By Yoshitsugu Tomokiyo**, Kunio Kaku*** and Tetsuo Eguchi**
}

\begin{abstract}
Extended dislocation nodes in $\alpha \mathrm{Cu}-\mathrm{Al}$ solid solution were observed by a transmission electron microscope, and the stacking fault energy (SFE) was determined. The specimens were annealed at $700^{\circ} \mathrm{C}$ after deformation to eliminate the effect of solute impedance force pinning partial dislocations. First, the variation in SFE with composition was measured and compared with Howie and Swann's data. It appears that differences between their values and ours are due to the solute impedance stress. The SFE in pure copper was also estimated as $46.4 \pm 2.7 \mathrm{erg} / \mathrm{cm}^{2}$ using Liu and Gallagher's relation. Secondly, the experiments were performed with $\mathrm{Cu}-15.9$ at \% Al quenched from different temperatures to study the effect of short range order (SRO) on the SFE. The SFE varies with the quenching temperature, and the results show a good correspondence with those of the electrical resistivity, hardness and specific heat measurements. The variation in SFE with the quenching temperature may be interpreted as being due to SRO rather than quenching stresses. The experiments suggest that SRO is not only responsible for the frictional effects as suggested by many workers, but also might affect the true SFE. The SFE decreases with development of SRO in the sample where stacking faults already exist. This effect of SRO is in the opposite sense to that found when the stacking faults are introduced to an ordered alloy.
\end{abstract}

(Received May 24, 1973)

\section{Introduction}

The stacking fault energy (SFE) of an $f c c$ metal is one of the important parameters determining its physical properties. Many experimental and theoretical studies have been performed with regard to SFE in metals and alloys ${ }^{(1)(2)}$, especially in $\mathrm{Cu}$-base alloys. The concentration and temperature dependence of SFE have recently been studied quantitatively by electron microscopic observation of the faults. It has been found that SFE depends on the composition in many kinds of alloys and decreases with increasing electronatom ratio. It is now believed that the node measurement is the most suitable method for determining SFE, though a number of other methods have been employed for its estimation. An extrapolation method has been proposed by Liu and Gallagher ${ }^{(3)}$, which enables us an accurate determination of SFE in pure metals in which the nodes are too small for the direct measurement. However, the values of SFE for pure copper determined by many workers with different methods differ considerably from one another ${ }^{(2)}$.

One has to be careful in determining SFE by the socalled node method, because the node size and shape are seriously affected by the conditions of deformation and heat treatment of the specimen. It has been pointed out that the nodes are prevented from reaching their most favorable equilibrium configuration by the internal stress or pinning of the adjacent dislocation lines, or by the solute impedance force, and that SFE

* This paper was originally published in Japanese in $\mathbf{J}$. Japan Inst. Metals, 36 (1972), 329.

** Department of Iron and Steel Metallurgy, Faculty of Engineering, Kyushu University, Fukuoka, Japan.

*** Graduate School, Kyushu University, Fukuoka. Present address: Wakayama Steel Works, Sumitomo Metals Industrial Ltd., Wakayama, Japan.

Trans. JIM as determined from the samples deformed at room temperature does not give its true magnitude ${ }^{(4)}$. In the deformed samples, the size and shape of faults vary so much on annealing that the apparent magnitude of SFE also changes ${ }^{(5)(6)}$. The factors which give an influence on the size and shape of faults on annealing are, for example, the segregation, the ordering, the temperature dependence of elastic constants, and that of the true SFE, besides the effects described above. There has been, however, some controversy concerning the effect of ordering on $\mathrm{SFE}^{(2)(6)}$. Though the presence of short range order (SRO) in $\alpha \mathrm{Cu}-\mathrm{Al}$ alloys has been shown from many experimental studies $^{(7) \sim(10)}$, only few studies have been made to investigate its effect on SFE.

In the present paper the concentration dependence of SFE is studied in $\alpha \mathrm{Cu}-\mathrm{Al}$ alloys by the node method, and SFE in pure copper is estimated using Liu and Gallagher's relation. The relationship between SFE and SRO is also studied in the quenched samples at room temperature. The results of electron microscopic observation are compared with those of electrical resistivity, specific heat and hardness measurements.

\section{Experimental Procedure}

The $\mathrm{Cu}-\mathrm{Al}$ alloys were prepared from $99.99 \% \mathrm{Cu}$ and $\mathrm{Al}$ in a vacuum induction furnace. The ingots were homogenized in vacuum at $800^{\circ} \mathrm{C}$ for $24 \mathrm{hr}$ and then cold-rolled to a thickness 0.1 to $0.2 \mathrm{~mm}$ with repeated annealing. These sheets were vacuum-annealed at $700^{\circ} \mathrm{C}$ for $5 \mathrm{hr}$ and cooled slowly in the furnace to eliminate residual stresses and solute impedance forces introduced by cold rolling. Since stable nodes do not disappear by this heat treatment, no further deformation was needed to introduce dislocation nodes. Chemical analysis of these sheets showed the composi-

1974 Vol. 15 
tion of the alloys as 5.3, 9.0, 13.5, 15.9 and 17.9 at \% Al.

The concentration dependence of SFE was studied by the observation of these furnace-cooled samples through an electron microscope. The effect of SRO on SFE was studied in a $\mathrm{Cu}-15.9$ at \% $\mathrm{Al}$ alloy. The furnace-cooled samples were kept at one of the various temperatures, either in an oil bath $\left(20\right.$ to $200^{\circ} \mathrm{C}$ ) or in a salt bath $\left(200\right.$ to $\left.700^{\circ} \mathrm{C}\right)$, and then quenched into iced brine. All the samples were electrolytically polished at room temperature and dislocation nodes were observed in a JEM-200 electron microscope. For the measurement of SFE isolated and symmetrical nodes were chosen so that the effect of the surface and the interactions between dislocations might be minimized. The inscribed and outer radii (expressed by $Y$ and $R$, respectively) were calculated from a geometric relation as suggested by Gallagher ${ }^{(4)}$. The microscope magnification was $\times 30000$, and the node parameters were measured by projecting an image in the original plates onto the screen with a further magnification of $\times 25$.

The measurement of resistivity was made on wires of $0.6 \mathrm{~mm}$ in diameter in liquid $\mathrm{N}_{2}$ by the method of double potentiometer.

The preparation method of the specimens and the hardness measurement are described in the previous paper $^{(11)}$.

\section{Result and Discussion}

\section{Estimation of SFE}

Equations with which one can obtain SFE $\gamma$ by the node method have been proposed by many workers. The relation between $\gamma, R$ and $Y$ proposed by Brown ${ }^{(12)}$ and Thölen ${ }^{(13)}$ is expressed in the following two equations:

$$
\begin{aligned}
\gamma R / G b_{p}^{2}= & 0.27-0.08\{v /(1-v)\} \cos 2 \alpha \\
& +[0.104(2-v) /(1-v) \\
& +0.24\{v /(1-v)\} \cos 2 \alpha] \log (R / \varepsilon) ; \\
\gamma Y / G b_{p}^{2}= & 0.055(2-v) /(1-v)-0.06\left\{v /(1-v)^{2}\right\} \\
& \times \cos 2 \alpha+[0.018\{(2-v) /(1-v)\} \\
& +0.036\{v /(1-v)\} \cos 2 \alpha] \log (R / \varepsilon) .
\end{aligned}
$$

The equations of Siems ${ }^{(14)(15)}$ are

$$
\begin{aligned}
\gamma R / G b_{p}^{2}= & (1 / 4 \pi)\left\{\psi_{0} /\left(\psi_{0}-1\right)\right\}[1 \\
& +v(1+3 \cos 2 \alpha) / 2(1-v)] \ln (R / \varepsilon) ; \\
\gamma Y / G b_{p}^{2}= & \left(\psi_{0} / 8 \sqrt{3} \pi\right)[\{2-v(1+2 \cos 2 \alpha)\} /(1-v)]
\end{aligned}
$$

where the parameter $\psi_{0}$ is given by the following expressions:

$$
\begin{aligned}
\psi_{0}-\ln \psi_{0}-1= & \{(\sqrt{3}-1) / 2\} \\
& \times[3(2-v) /\{2-v(1+2 \cos 2 \alpha)\} \\
& -1] \ln (R / \varepsilon) \\
& \psi_{0}=\sqrt{3}(Y / d) \\
d= & \left(G b_{p}^{2} / 8 \pi \gamma\right)\{(2-v) /(1-v)\} \\
& \times[1-\{2 v /(2-v)\} \cos 2 \alpha] .
\end{aligned}
$$

Jøssang et al. ${ }^{(16)}$ also suggested an equation for $\gamma$, whose actual formula is omitted here. In the above expressions, $G$ is the elastic shear modulus, $v$ Poisson's ratio, $b_{p}$ the partial dislocation Burgers vector, $\alpha$ the character angle of the dislocation, $d$ the distance between the extended partial dislocations, and $\varepsilon$ is the cut off radius. These equations assume an isolated symmetric node in an infinite medium with elastic isotropy, and therefore they are, strictly speaking, valid only for isolated symmetrical nodes. Thus it is necessary to exclude the distorted and asymmetrical nodes from our investigation. The nodes which lie apparently close to the specimen surfaces were also excluded.

From the measured values for $R$ and $Y$, SFE can be calculated by the equations, when the values of $\alpha, G$, $v, b_{p}$, and $\varepsilon$ are known. In this paper $\gamma$ has been obtained using the values $G=4 \times 10^{11}$ dyne $/ \mathrm{cm}^{2}$, $v=0.33$, and $b_{p}=\varepsilon=1.5 \AA$. Since all the character angles have not necessarily been measured, we have used the value $\alpha=30^{\circ}$. The values of $\alpha$ which happened to be directly measured were all close to $30^{\circ}$. The fact that $\alpha$ is nearly equal to $30^{\circ}$ was reported for $\mathrm{Co}-\mathrm{Ni}^{(17)}, \mathrm{Ag}-\mathrm{In}^{(4)}$, and $\mathrm{Ag}-\mathrm{Sn}^{(18)}$ alloys. Tisone et al. ${ }^{(19)}$ showed that the distribution of $\alpha$ has a peak near $30^{\circ}$ for the nodes in $\mathrm{Cu}-15$ at \% Al thermally treated after deformation. Even if an exact measurement of $\alpha$ is difficult, the value of $\alpha$ can be evaluated from $R / Y$ by using Brown's equation. The mean value of $\alpha$ thus evaluated indirectly for 90 nodes has been $26^{\circ} \pm 9^{\circ}$. The variation of $\alpha$ gives $\pm 4 \%$ and $3 \%$ errors to $\gamma R / G b_{p}^{2}$ and $\gamma Y / G b_{p}^{2}$, respectively. In any way the error in the value $\gamma$ due to the uncertainty of $\alpha$ is less than the error due to uncertainties of $R$ and $Y$. The variation of $4 \%$ in the value of $v$ produces an error of $1.5 \%$ in $\gamma R / G b_{p}^{2}$. An uncertainty in the shear modulus $G$ produces a serious error in $\gamma$, since $\gamma$ is directly proportional to $G$. If the value of $G$ varies from $4.0 \times 10^{11}$ (for pure copper) to $4.6 \times 10^{11}$ dyne $/ \mathrm{cm}^{2}$ (for $\mathrm{Cu}-15$ at $\% \mathrm{Al}$ alloy) the variation in $\gamma R / G b_{p}^{2}$ is about $15 \%$. There were considerable dispersions in the measured values of $R$ and $Y$, and accordingly not only the mean values for $R$ and $Y$ but also the $95 \%$ confidence interval was calculated by assuming that the measured $R$ and $Y$ are normally distributed around their mean values.

The dispersion in $R$ and $Y$ may be mainly caused by the electron diffraction effect, errors in the magnification, and possibly the influence of adjacent dislocations or free surfaces $\dagger$. The rolling texture led the specimen normal close to [110], and most of the observed nodes planes had an inclination of about $30^{\circ}$ to the foil surface. The nodes were observed in a bright field using either the 002 or 111 type reflection.

\section{Concentration dependence of SFE}

In Photos. 1 and 2 typical examples of dislocation

$\dagger$ In order to avoid the uncertainty due to the influence of image forces, the method adopted by Imura et al. ${ }^{(20)}$ using a single crystal with its surface parallel to the (111) plane, would have been effective. However, we have not used the method for technical reasons. 


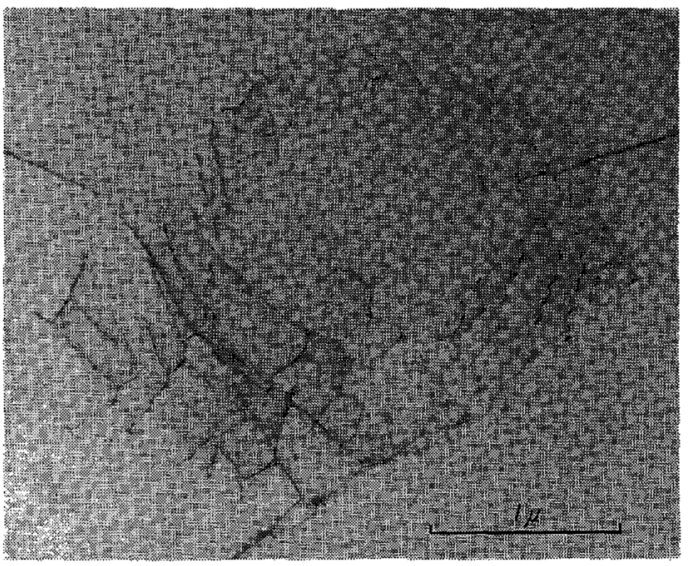

Photo. 1 The dislocation network in $\mathrm{Cu}-15.9$ at \% $\mathrm{Al}$ annealed at $700^{\circ} \mathrm{C}$ for $5 \mathrm{hr}$ after deformation.

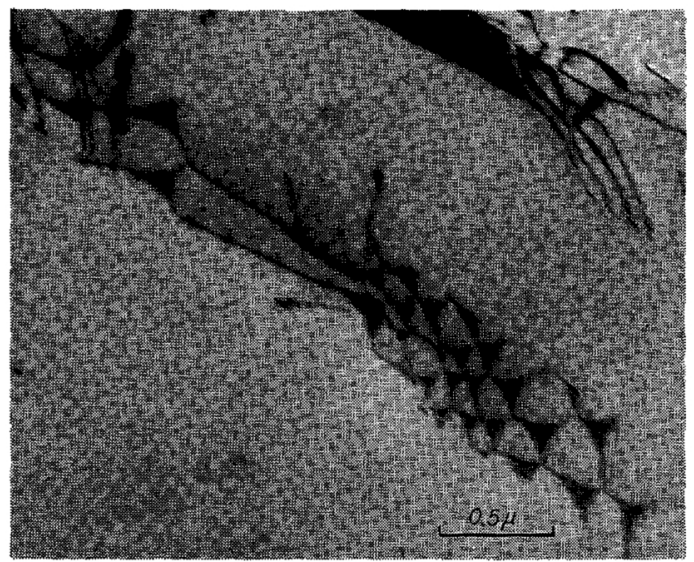

Photo. 2 The network of extended dislocations in $\mathrm{Cu}-15.9$ at \% Al. The variation in the node size and shape indicates the effect of the surface and interactions between dislocations.

networks in $\mathrm{Cu}-\mathrm{Al}$ alloys are shown. Though the nodes are more symmetrical than those observed in the specimens deformed at room temperature, there is still a variation in the node size and shape because of the effect of surfaces and of the interaction with adjacent partial dislocations. The variation of node size with the solute concentration in $\mathrm{Cu}-\mathrm{Al}$ alloys is shown

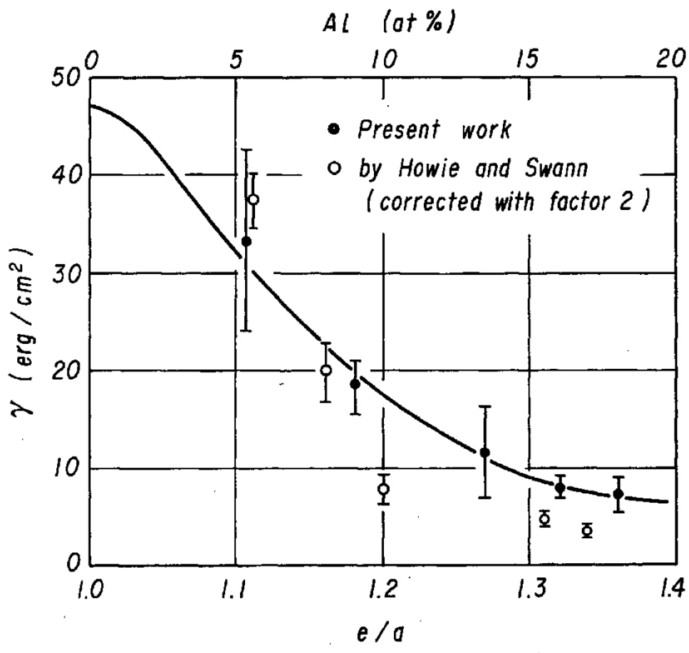

Fig. 1 Stacking fault energy plotted against the electron per atom ratio. Solid curve represents the SFE determined by the least squares method using Liu and Gallagher's relation ${ }^{(3)}$.

in Photo. 3. The node size increases, as expected, with the increase in $\mathrm{Al}$ concentration. The values of SFE calculated by different methods, namely by the equations of Brown, Siems and Jøssang are listed in Table 1 together with the Al concentration or the electronatom ratio. The results calculated by Brown's equation are plotted against electron-atom ratio in Fig. 1, where the results of Howie and Swann ${ }^{(21)}$, as corrected by Brown ${ }^{(12)}$ by a factor 2 , are also plotted for comparison.

As can be seen in Fig. 1 the present values of $\gamma$ are larger than those of Howie and Swann at high $\mathrm{Al}$ concentrations. The discrepancy may be due to the differences in the experimental procedures. The specimens used in the present measurements were annealed at high temperatures and slowly cooled to room temperature after deformation. The measurements of SFE reported by Howie and Swann, however, referred to the specimens deformed at room temperature without any subsequent heat treatment. If we assume that the true SFE can be obtained with specimens annealed after deformation, the solute impedance stress $\tau_{f}$ at room temperature is given by the following equation
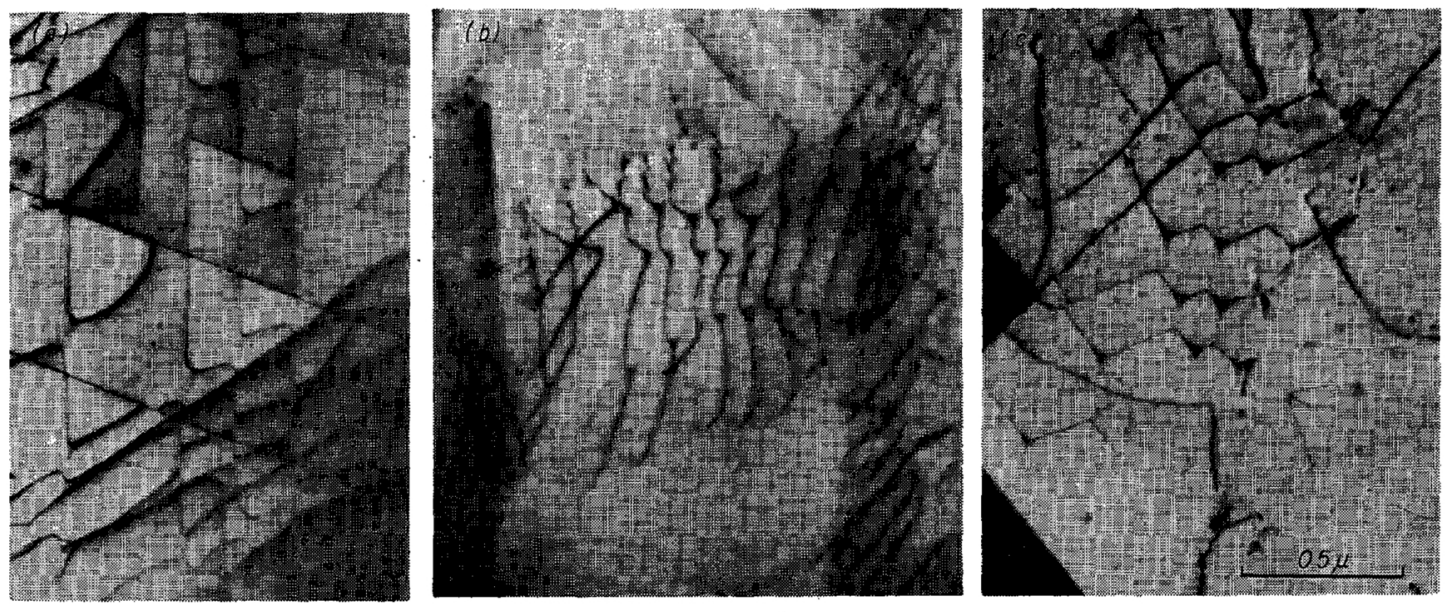

Photo. 3 The variation in node size with $\mathrm{Al}$ concentration.
(a) 5.3 at $\% \mathrm{Al}$,
(b) 9.0 at \% Al,
(c) 15.9 at $\% \mathrm{Al}$. 
Table $1 \mathrm{Al}$ concentrations and stacking fault energies calculated by different methods.

\begin{tabular}{|c|c|c|c|c|c|c|c|}
\hline $\operatorname{Al}(a t \%)$ & 5.3 & 9.0 & 13.5 & 15.9 & 17.9 & \multirow{2}{*}{\multicolumn{2}{|c|}{$\begin{array}{l}\text { Method of } \\
\text { calculation }\end{array}$}} \\
\hline$e / a$ & 1.06 & 1.18 & 1.27 & 1.32 & 1.36 & & \\
\hline $\begin{array}{c}\gamma \\
\left(\mathrm{erg} / \mathrm{cm}^{2}\right)\end{array}$ & $\begin{array}{l}33.0 \pm 9.6 \\
22.3 \pm 1.1 \\
28.7 \pm 8.3 \\
29.6 \pm 1.5 \\
27.5 \pm 1.4\end{array}$ & $\begin{array}{l}18.0 \pm 2.7 \\
17.1 \pm 2.2 \\
16.1 \pm 2.4 \\
23.3 \pm 3.0 \\
20.5 \pm 2.7\end{array}$ & $\begin{array}{r}11.5 \pm 4.6 \\
13.9 \pm 2.1 \\
9.7 \pm 1.4 \\
18.5 \pm 2.8 \\
16.4 \pm 2.5\end{array}$ & $\begin{array}{r}8.0 \pm 0.6 \\
8.7 \pm 1.0 \\
6.8 \pm 0.5 \\
11.5 \pm 1.3 \\
10.5 \pm 1.2\end{array}$ & $\begin{array}{r}7.2 \pm 1.6 \\
11.8 \pm 1.5 \\
6.2 \pm 1.4 \\
15.7 \pm 2.0 \\
13.6 \pm 1.8\end{array}$ & $\begin{array}{l}\text { Siems }^{(14)} \\
\text { Jøssang } \\
(16)\end{array}$ & $\begin{array}{l}(R) \\
(Y) \\
(R) \\
(Y) \\
(Y)\end{array}$ \\
\hline
\end{tabular}

as proposed by Swann et al. ${ }^{(6)(22)}$ :

$$
\tau_{f}=\left(\gamma-\gamma_{\text {app }}\right) / b_{p}
$$

where $\gamma_{\text {app }}$ is the apparent SFE evaluated for the specimens deformed at room temperature. From the difference in $\gamma$ between the present result and that of Howie and $\mathrm{Swann}^{(21)}$ in the $\mathrm{Cu}-15$ at \% $\mathrm{Al}$ alloy the solute impedance stress was calculated to be $\tau_{f}=$ $1.4 \pm 0.3 \mathrm{~kg} / \mathrm{mm}^{2}$. This value is equal to the difference of the critical resolved shear stresses between the alloy and pure copper ${ }^{(23)}$. For the lower Al concentration the present values of SFE agree with those of Howie and Swann within the experimental errors. This may be due to the reduction of the effect of solute impedance force with decrease in $\mathrm{Al}$ concentration. As can be seen in Fig. 2, the dispersion of $\gamma$ for $\mathrm{Cu}-5.3$ at $\% \mathrm{Al}$ is large because of the small node size. For the alloys with lower Al concentration in which SFE is higher, the weak beam technique would be desirable for determining SFE with high accuracy.

In order to estimate the value of SFE for pure copper from the present results, the relation obtained by Liu for and Gallagher ${ }^{(3)}$ for Ag alloys was used, namely

$$
\gamma=\gamma_{0} \exp \left[K\left\{C^{2} /(1+C)^{2}\right\}\right],
$$

where $\gamma_{0}$ and $\gamma$ are SFE of the solvent metal and the alloys, respectively. $C=X / X_{0}$, where $X$ is the alloying concentration in at $\%, X_{0}$ the solubility limit at high temperature, and $K$ is a constant for the alloy system. Equation (9) is rewritten as below by taking its logarithm:

$$
\ln \gamma=K C^{2} /(1+C)^{2}+\ln \gamma_{0} .
$$

If there is a straight line relationship between the observed values for $\ln \gamma$ and $C^{2} /(1+C)^{2}, \gamma_{0}$ can be obtained directly from the extrapolated intercept on the vertical axis at $C=0$. Figure 2 is a plot of $\ln \gamma$ vs $C^{2} /(1+C)^{2}$ where $\gamma$ is obtained by Brown's equation. Assuming the magnitude of $X_{0}$ to be 18 at $\%$, we obtain from the result shown in Fig. 2 the extrapolated value of $\gamma$ for pure copper as

$$
\gamma_{\mathrm{Cu}}=46.4 \pm 2.7 \mathrm{erg} / \mathrm{cm}^{2} \text {, }
$$

with

$$
K=-7.7 \pm 0.3
$$

The values of $\gamma$ for pure copper published in the literature vary from $20 \mathrm{erg} / \mathrm{cm}^{2(24)}$ to $169 \mathrm{erg} / \mathrm{cm}^{2(25)}$, and yet Pande ${ }^{(26)}$ obtained the value $\gamma_{\mathrm{Cu}}=94 \pm 30$ $\mathrm{erg} / \mathrm{cm}^{2}$ using the same relation as above for $\mathrm{Cu}-\mathrm{Al}$ alloys. Howie and $\operatorname{Swann}^{(21)}$ concluded that $\gamma_{\mathrm{Cu}}$

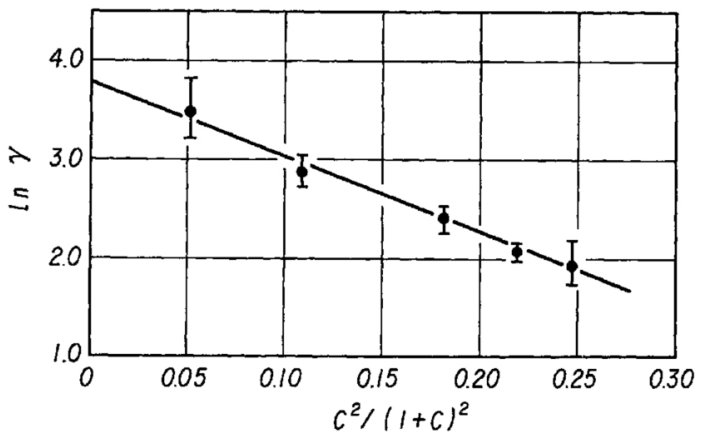

Fig. 2 Plot of $\ln \gamma$ vs $C^{2} /(1+C)^{2}$ of Cu-15.9 at \%A1 alloys, where $C=X / X_{0}$, and $X$ and $X_{0}$ represent the alloying concentration and the solubility limit at high temperature in at \%, respectively.

might be less than $60 \mathrm{erg} / \mathrm{cm}^{2}$. The present value agrees with the one obtained by Peterson and Queeney ${ }^{(27)}$ who determined SFE directly from the balance of the tensions at the interface of a stacking fault and a high angle grain boundary. Recently, the value of $\gamma_{\mathrm{Cu}}=$ $41 \pm 9 \mathrm{erg} / \mathrm{cm}^{2}$ has been obtained by Cockayne et al. ${ }^{(28)}$ using the so-called weak beam technique. Thus the present value of $\gamma_{\mathrm{Cu}}$ may be quite reasonable.

\section{Quenching temperature dependence of SFE}

The variations of the reciprocal of $Y$ or $R$ in $\mathrm{Cu}-$ 15.9 at $\% \mathrm{Al}$ alloy are plotted against the quenching temperature in Fig. 3. According to Brown's equations SFE is approximately in proportion to $G / R$ or $G / Y$. The changes in $Y^{-1}$ and $R^{-1}$, therefore, indicate the changes in SFE. It is apparent from Fig. 3 that the values of $R / Y$ are approximately constant and nearly equal to 5 , which is in accord with Brown's theory that $R / Y$ primarily depends on $\alpha$ but hardly on SFE. It thus appears that SFE may be calculated with considerably high accuracy from either $R$ or $Y$. As can be seen in Fig. 3, SFE depends on the quenching temperature. It can be considered that the observed SFE shows the reversible change with temperature because the specimens were slowly cooled to room temperature from $700^{\circ} \mathrm{C}$ in the furnace after deformation. A slight decrease in SFE is seen at temperatures in the range from 100 to $200^{\circ} \mathrm{C}$, and the maximum in SFE is observed at a temperature between 300 and $400^{\circ} \mathrm{C}$. The result of the present experiment is qualitatively in agreement with that of Tisone et al. ${ }^{(19)}$ but is different from that of Yoshioka et al. (29)

Possible causes for the change in SFE with temperature observed in the present experiment may be the 


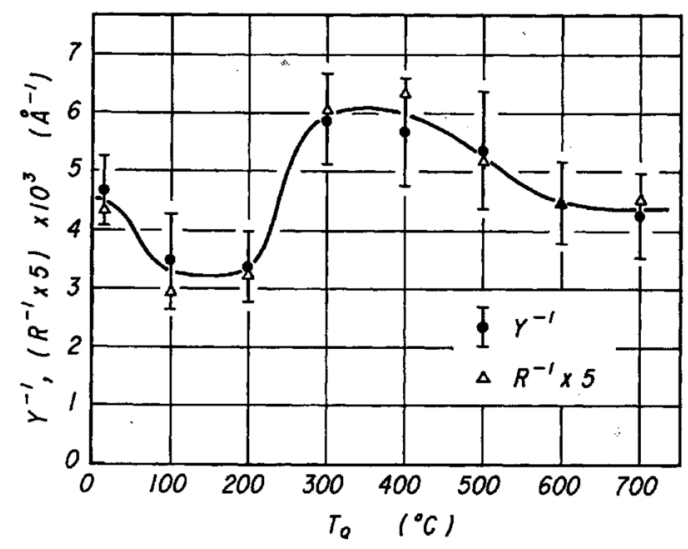

Fig. 3 Values of $Y^{-1}$ and $R^{-1}$ as functions of quenching temperature. The specimens with 15.9 at $\% \mathrm{Al}$ were annealed at $700^{\circ} \mathrm{C}$ and slowly cooled after deformation.

segregation, SRO, and the temperature dependence of the shear modulus, and that of the true SFE. According to Suzuki ${ }^{(30)(31)}$ it is expected that the node size increases with segregation and consequently SFE decreases. Since the tendency of solute segregation is approximately in proportion to $\partial \gamma / \partial c$ the segregation effect may not be remarkable in a high $\mathrm{Al}$ concentration alloy such as $\mathrm{Cu}-15.9$ at \% $\mathrm{Al}$ alloy in which the value of $\partial \gamma / \partial c$ is small as can be seen in Fig. 1. It seems fairly improbable that the segregation takes place at low temperatures below about $200^{\circ} \mathrm{C}$ in the sample which is annealed at $700^{\circ} \mathrm{C}$ and subsequently cooled slowly. Recently, the study of the temperature dependence of $\mathrm{SFE}$ in $\mathrm{Cu}-\mathrm{Al}$ alloys has been made by Hasegawa et al. ${ }^{(32)}$ using a hot stage in an electron microscope. They showed a linear dependence of SFE on temperature above $200^{\circ} \mathrm{C}$, although the shear modulus decreases linearly with increasing temperature. The disagreement between the present result and that of

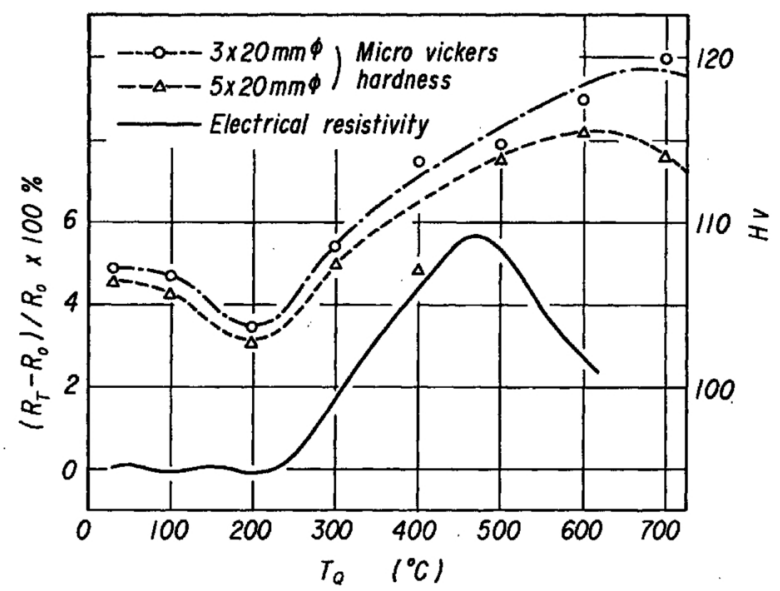

Fig. 4 The variation of electrical resistivity and micro Vickers hardness as functions of quenching temperature in $\mathrm{Cu}-15.5$ at $\% \mathrm{Al}^{(11)}$.

Hasegawa et al. at high temperature suggests that a certain change other than the solute segregation occurs in the alloy during the quench, so that the quenching of the equilibrium state at temperatures above $500^{\circ} \mathrm{C}$ may be impossible. Thus the decrease in SFE at high quenching temperature seems to be due to SRO.

Figure 4, in which the changes in electrical resistance and micro Vickers hardness are plotted against the quenching temperature, shows a good correspondence to Fig. 3. As in the measurement of SFE, the annealed specimen was kept at one of the various temperatures either in an oil bath or in a salt bath, and before each measurement of resistance the specimen was quenched. The change in the resistance relative to the one when the same specimen is slowly cooled is also shown in the figure. A slight change in the resistance below $250^{\circ} \mathrm{C}$ may be due to the ordering. This may be attributed to the fact ${ }^{(9)(11)(33) \sim(35)}$ that the equilibrium states are not achieved by furnace cooling below
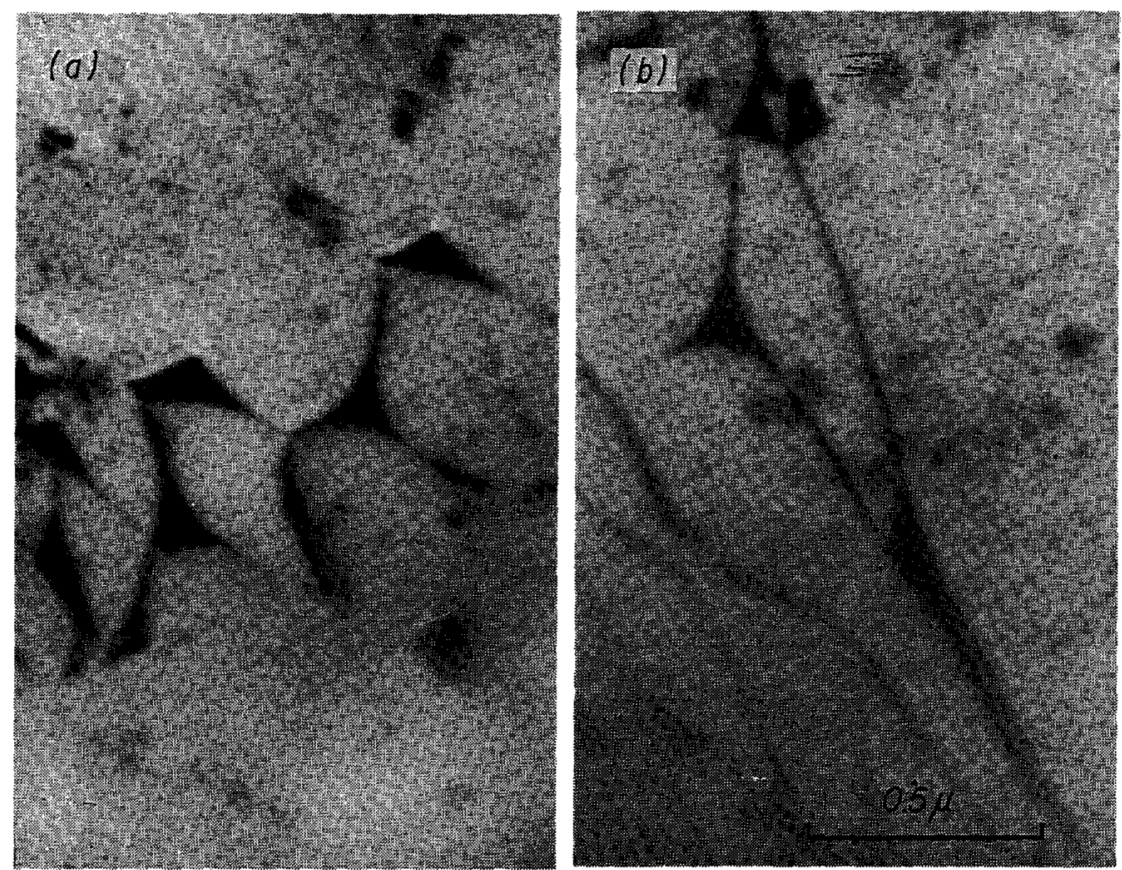

Photo. 4 The variation of node size in $\mathrm{Cu}-15.9$ at $\% \mathrm{Al}$ on annealing. (a) quenched from $400^{\circ} \mathrm{C}$, (b) annealed at $200^{\circ} \mathrm{C}$ for $24 \mathrm{hr}$ after quenching. 

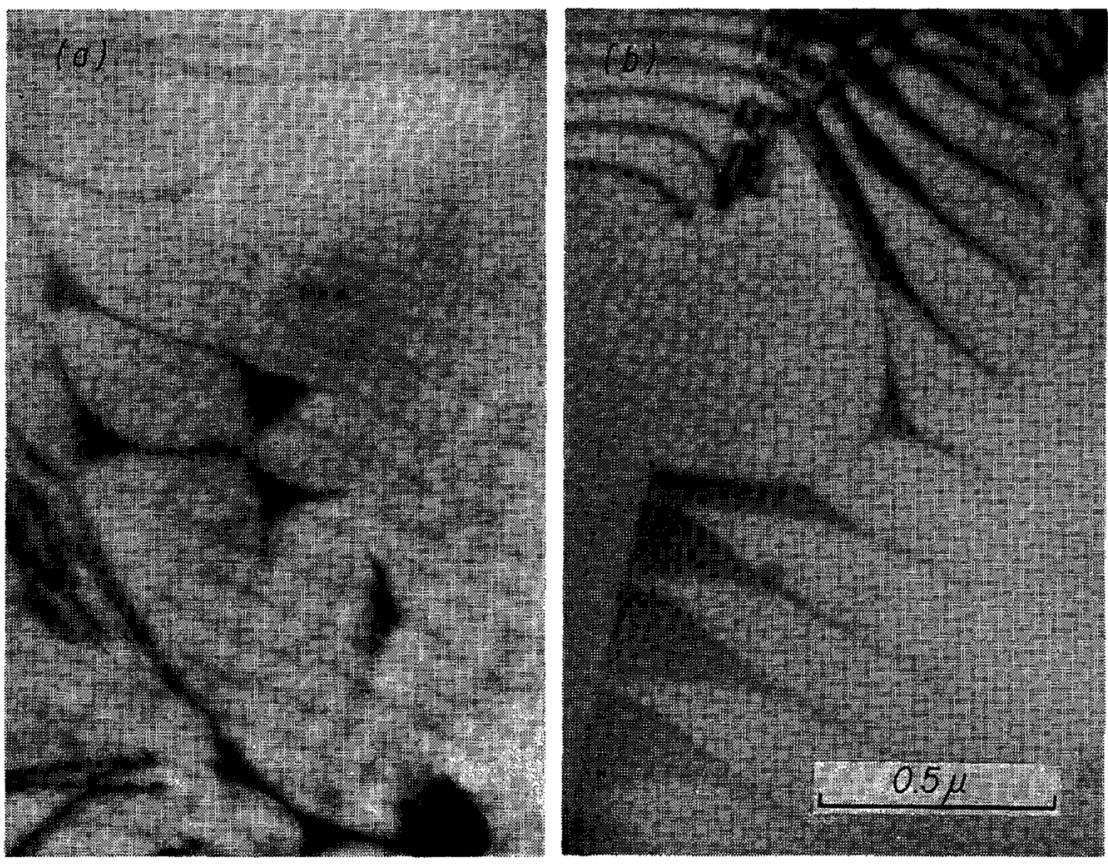

Photo. 5 The variation of node size in $\mathrm{Cu}-15.9$ at $\% \mathrm{Al}$ on annealing. (a) quenched from $600{ }^{\circ} \mathrm{C}$, (b) annealed at $200^{\circ} \mathrm{C}$ for $24 \mathrm{hr}$ after quenching.

$200^{\circ} \mathrm{C}$. A steep increase in resistance above $250^{\circ} \mathrm{C}$ is due to the destruction of SRO. The resistance begins to decrease when the quenching temperature becomes as high as $450^{\circ} \mathrm{C}$. A similar result has been reported

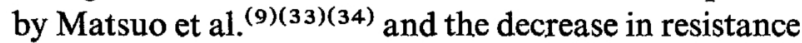
at high quenching temperature is attributed by them to the reordering stimulated by the presence of excess vacancies, namely, the ordering is more likely to occur during quenching from $600^{\circ} \mathrm{C}$ than from $450^{\circ} \mathrm{C}$. In the specific heat measurement a similar effect of SRO to the above has been observed and the result of microVickers hardness also shows that the quenching of the state of high temperature is imperfect ${ }^{(11)}$.

In order to examine the effect of SRO on SFE the specimens of $\mathrm{Cu}-15.9$ at \% $\mathrm{Al}$ alloy were annealed at $200^{\circ} \mathrm{C}$ for $24 \mathrm{hr}$ after quenching from 400,500 , or $600^{\circ} \mathrm{C}$ before $R$ and $Y$ are measured. The examples of nodes in the quenched and annealed specimens are shown in Photos. 4 and 5. Figure 5 illustrates $\Delta R^{-1}$, $\Delta Y^{-1}$ against the quenching temperature, where $\Delta R^{-1}=R_{a}^{-1}-R_{a}^{-1}$ and $\Delta Y^{-1}=Y_{a}^{-1}-Y_{a}^{-1}$, and the subscripts $q$ and $a$ represent quenching and an-

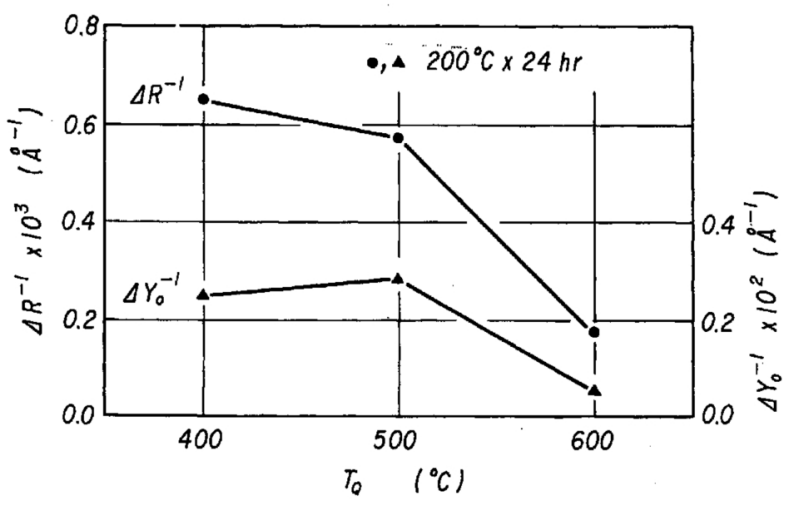

Fig. 5 Plot of $R_{q}^{-1}-R_{a}^{-1}$ and $Y_{q}^{-1}-Y_{a}^{-1}$ as functions of quenching temperature in $\mathrm{Cu}-15.9$ at $\% \mathrm{Al}$. nealing, respectively. As mentioned above, $\Delta R^{-1}$ and $\Delta Y^{-1}$ exhibit the changes in SFE. It is clear from Fig. 5 that SFE is decreased by annealing after quenching. If there exists an effect of thermal stress due to quenching, $\Delta R^{-1}$ and $\Delta Y^{-1}$ should be greater for the specimen quenched from $600^{\circ} \mathrm{C}$ than for the one quenched from $400^{\circ} \mathrm{C}$. Actually, however, the result is opposite. The result that the amount of decrease in SFE is greater in the specimen quenched from $400^{\circ} \mathrm{C}$ than in the one quenched from $600^{\circ} \mathrm{C}$ may be attributed to the difference in amounts of SRO. It is expected from the result of the resistance measurement that a higher degree of order is obtained for the specimen quenched from $600^{\circ} \mathrm{C}$ than for the one quenched from $400^{\circ} \mathrm{C}$. Therefore, during the annealing at $200^{\circ} \mathrm{C}$ a larger amount of SRO may be produced for the specimen quenched from $400{ }^{\circ} \mathrm{C}$. From the above argument it seems that SFE decreases with the development of SRO. Gallagher ${ }^{(2)}$ has observed a slight increase in node size for the specimen cooled from $320^{\circ} \mathrm{C}$ to room temperature. This result is also explained in terms of the onset of SRO.

Most investigations which are concerned with the effect of SRO on SFE have been made by introducing the stacking faults to the specimens with different degrees of order ${ }^{(6)(23)(36)}$. In these investigations it has been concluded that SFE was greater in the ordered structure than in the disordered one with the same composition, since a high stress was necessary to introduce the stacking faults in the former. Kamada ${ }^{(37)}$ and Thomas ${ }^{(38)}$ also suggested that an extra stress is necessary to push a partial dislocation through an alloy with SRO and the apparent SFE should therefore be high. Mikkola and Cohen ${ }^{(39)}$, however, found by $\mathrm{X}$-ray measurement that specimens which were slowly cooled prior to filing, thus having a higher initial degree of order, gave higher fault probabilities than 
quenched specimens, which suggests that the partial dislocations are widely spaced, namely, SFE is lower when SRO is present.

Thus the node size is very sensitive to the thermal and mechanical treatment of the specimen. As shown in the present experiment the development of SRO in the neighborhood of the existing fault causes the decrease in SFE. This effect is in the opposite sense to that postulated when a stacking fault is introduced to an ordered alloy.

\section{Conclusions}

The SFE was measured by the node method for $\mathrm{Cu}$ $\mathrm{Al}$ alloys and the results were compared with the measurements of the electrical resistance and microVickers hardness. The major conclusions obtained from the present study are as follows:

(1) The results for the concentration dependence of SFE are qualitatively in good agreement with that of Howie and Swann. The differences in the magnitude of SFE at high $\mathrm{Al}$ are due to the solute impedance stresses.

(2) SFE of pure copper is estimated to be $46.6 \pm$ $3.7 \mathrm{erg} / \mathrm{cm}^{2}$, using Liu and Gallagher's equation.

(3) SFE depends on the quenching temperature and the result obtained corresponds reasonably to the ones of electrical resistance, micro-Vickers hardness and specific heat.

(4) The effect of SRO on SFE depends on the conditions of deformation and heat treatment. If specimens are annealed after deformation, SFE depends on the temperature of quenching which precedes the measurement and it decreases with the development of SRO.

\section{REFERENCES}

(1) A. W. Ruff, Jr.: Met. Trans., 1 (1970), 2391.

(2) P. C. J. Gallagher: Met. Trans., 1 (1970), 2429.

(3) Y. C. Liu and P. C. J. Gallagher: J. Metals, 21 (1969), 93A.

(4) P. C. J. Gallagher: J. Appl. Phys., 37 (1966), 1710.

(5) D. McLean: J. Inst. Metals, 91 (1963), 382.

(6) J. W. Christian and P. R. Swann: AIME Conf. Ser., Alloying Behavior in Concentrated Solid Sotution, Gorden and Breach, (1965).
(7) C. R. Houska and B. L. Averbach: J. Appl. Phys., 30 (1959), 1525.

(8) R. W. Cahn and R. G. Davies: Phil. Mag., 5 (1960), 1119.

(9) S. Matsuo and L. M. Clarebrough: Acta Met., 11 (1963), 1195.

(10) B. Borie and C. J. Sparks, Jr.: Acta Cryst., 17 (1964), 827.

(11) C. Kinoshita, Y. Tomokiyo, H. Matsuda and T. Eguchi: Trans. JIM, 14 (1973), 91.

(12) L. M. Brown: Phil. Mag., 10 (1964), 441.

(13) L. M. Brown and A. R. Thölen: Discuss. Faraday Soc., 37-38 (1964), 35.

(14) R. Siems, P. Delavignette and S. Amelinckx: Z. Phys., 165 (1961), 35.

(15) R. Siems: Discuss. Faraday Soc., 37-38 (1964), 42.

(16) T. Jøssang, M. J. Stowell, J. P. Hirth and J. Lothe: Acta Met., 13 (1965), 279.

(17) T. Ericson: Acta Met., 14 (1966), 853.

(18) A. W. Ruff, Jr. and L. K. Ives: Can. J. Phys., 45 (1967), 787.

(19) T. C. Tisone, J. O. Brittain and M. Meshii: Phys. Status Solidi, 27 (1968), 185.

(20) T. Imura and Y. Enokido: J. Phys. Soc. Japan, 26 (1969), 869.

(21) A. Howie and P. R. Swann: Phil. Mag., 6-II (1961), 1215.

(22) P. R. Swann: Discuss. Faraday Soc., 37-38 (1964), 84.

(23) J. B. Cohen and M. E. Fine: J. physique, 23 (1962), 749.

(24) J. P. Hirth and J. Lothe: Theory of Dislocations, McGrawHill, New York, (1968), p. 763.

(25) A. Seeger, R. Berner and H. Wolf: Z. Phys., 155 (1959), 247.

(26) C. S. Pande: Phys. Status Solidi, 37 (1970), 151.

(27) L. G. Peterson and R. A. Queeney: Trans. Met. Soc. AIME, 245 (1969), 2098.

(28) D. J. H. Cockayne, M. L. Jenkins and I. L. F. Ray: Phil. Mag., 24 (1971), 1383.

(29) S. Yoshioka, Y. Nakayama and T. Ito: J. Japan Inst. Metals, 29 (1965), 778 (in Japanese).

(30) H. Suzuki: J. Phys. Soc. Japan, 17 (1962), 322.

(31) H. Suzuki: Sci. Rep. Inst. Tohoku Univ., A4 (1952), 455.

(32) T. Hasegawa, K. Asou and S. Karashima: Met. Trans., to be published.

(33) M. S. Wechsler and R. H. Kernohan: Acta Met. 7 (1959), 599.

(34) V. Ye. Panin, V. P. Fadin, V. P. Redkin and V. A. Ignatyuk: Phys. Met. and Metallog., 15, No. 2(1963), 87.

(35) C. R. Brooks and E. E. Stansbury: Acta Met., 11 (1963), 1303.

(36) P. R. Swann and J. Nutting: J. Inst. Metals, 90 (1961 62), 133.

(37) K. Kamada: J. Appl. Phys., 39 (1968), 1824.

(38) G. Thomas: J. Aust. Inst. Metals, 91 (1963), 382.

(39) D. E. Mikkola and J. B. Cohen: J. Appl. Phys., 33 (1962), 892. 